Revista de Psicología de la PUCP. Vol. XXIII, 1, 2005

\title{
La capacidad para perdonar desde una perspectiva psicológica
}

\author{
María Martina Casullo' \\ Universidad de Buenos Aires
}

\begin{abstract}
Se presenta una escala diseñada para la evaluación de la Capacidad de Perdonar, administrada a una muestra de 800 adultos (50\% varones y $50 \%$ mujeres) de la población general de la Ciudad de Buenos Aires y el Conurbano Bonaerense. Se analizan datos preliminares relacionados con las variables sexo, edad y nivel de religiosidad, así como diferentes concepciones teóricas -psicológicas y filosóficas- sobre el concepto perdón. Se encontró que las mujeres son más perdonadoras que los varones y que el perdonar aparece asociado a la presencia de creencias acerca del mismo. El $88 \%$ de los varones y el $95 \%$ de las mujeres entrevistadas consideran importante ser capaces de perdonar.
\end{abstract}

Palabras clave: perdón, evaluación psicológica, población general.

\section{The capacity to forgive from a psychological perspective}

A scale developed to assess the capacity to forgive, administered to 800 adults ( $50 \%$ males and $50 \%$ females) from the general population of the city of Buenos Aires and its suburban area (N: 800 ), is presented. Preliminary research data related to gender, age and religiosity are analyzed, as well as different psychological and philosophical conceptions. We found that women show a higher capacity to forgive than men and that forgiveness is associated to the presence of beliefs about it. According to our results, $88 \%$ of men and $95 \%$ of women consider that it is important to be able to forgive.

Keywords: forgiveness, psychological assessment, general population.

1 Doctora en Psicología. Profesora en la Facultad de Psicología de la Universidad de Buenos Aires, Argentina. Directora del Doctorado en Psicología de la Universidad de Palermo, Argentina. Investigadora independiente del Consejo Nacional de Investigaciones Científicas y Técnicas (CONICET). Correo electrónico:

macasullo@speedy.com.ar 

La vida cotidiana ofrece oportunidades diversas en las que es posible constatar que las personas dicen perdonar o piden ser perdonadas.

¿Qué factores o variables psicológicas están en juego en el proceso del perdón? ¿Cuáles son sus fundamentos? ¿Cómo se estructura, a lo largo del ciclo de vida, esta capacidad o posibilidad? ¿Poder perdonar tiene consecuencias relevantes para la salud mental y física o las relaciones interpersonales? ¿Corresponde ocuparse del perdón en el transcurso de un proceso terapéutico o de asesoramiento psicológico?

El concepto perdón ha recibido poca atención sistemática desde la psicología como disciplina científica. La historia de su estudio, en el campo de la psicología y las ciencias sociales, puede dividirse en dos períodos según McCullough, Pargament y Thoresen (2000): el primero se ubica entre los años 30s y 80s del siglo XX; existen planteos teóricos sobre el tema e investigaciones empíricas modestas. El segundo período abarca desde los años 80 s hasta el presente y en él es posible ubicar trabajos que se ocupan del tema de manera más seria e intensiva.

Autores como Piaget (1932) y Behn (1932) analizaron el perdonar en relación con el desarrollo del juicio moral. Pueden mencionarse también estudios de consejeros psicológicos que, en el campo del counseling pastoral, plantearon la vinculación entre el perdonar y el logro de la salud mental (Angyal, 1952; Beaven, 1951). Rokeach (1973) se ubica como uno de los antecesores más importantes dado su interés por el estudio de los valores humanos, que categoriza en instrumentales y terminales. El investigador 
menciona la capacidad de perdonar entre los dieciocho valores instrumentales que propone.

Enright, Santos y Al-Mabuk (1989) se ocuparon de vincular la posibilidad de perdonar con las propuestas de Kohlberg (1976) sobre el desarrollo moral y el sentido de justicia. Algunos clínicos comienzan a ocuparse del tema (Fitzgibbons, 1986; Hope, 1987; Jampolsky, 1980) destacando el efecto salugénico del perdonar. A comienzos de los años 90 varios investigadores comienzan a indagar sobre los principios o reglas psicosociales subyacentes (Boon \& Sulsky, 1997).

Si bien puede afirmarse que los estudios han ido en aumento, las concepciones teóricas sobre el tema son diversas y no hay consenso. Como bien lo señalan Enright y Coyle (1998), el concepto psicológico perdonar no debe confundirse con el legal de indulto, con condonar (que implica una justificación de un hecho) o excusar (que supone que existen razones para obrar de una manera determinada). Ciertos autores señalan la diferencia entre perdón y reconciliación (reestablecimiento de un vínculo); el perdón supone una voluntad subjetiva de abandonar el resentimiento, los juicios negativos y la indiferencia hacia quien nos ha injuriado o lastimado y poder desarrollar sentimientos de compasión y generosidad. Para McCullough et al. (2000) la esencia del perdonar implica cambios de tipo prosocial en las motivaciones personales hacia la persona, grupo o situación que ha lastimado o injuriado. Desde su experiencia en el trabajo con parejas, Hargrave y Sells (1997) definen al perdón en términos de: 1) permitir al victimario reconstruir un vínculo quebrado, y 2) favorecer una discusión abierta sobre la violación relacional de manera tal que víctima y victimario puedan trabajar en la reconstrucción de tal vínculo.

Puede decirse que todas las definiciones psicológicas formuladas sobre el perdonar parecen centrarse en un factor común: 
cuando los sujetos perdonan, sus comportamientos (pensamientos, sentimientos, acciones) hacia quien es objeto del perdón se transforman en más positivos. Perdonar implica un cambio interno y al mismo tiempo prosocial hacia una figura o situación percibida como transgresora, en el contexto de un vínculo interpersonal. Perdonar supone tanto una dimensión subjetiva intrapsíquica como otra interpersonal, por lo cual se sugiere pensar el perdón como un constructo psicosocial; ejercen enorme influencia en su definición y aceptación variables de tipo religioso, ideológico-políticas, culturales y socio-históricas.

No todos los autores coinciden en considerar el perdonar como beneficioso. Para algunos, el perdonar hace a los sujetos más vulnerables a la revictimización en los vínculos interpersonales cuando ha habido experiencias de abuso y maltrato.

Para que aparezca la necesidad del perdón debe haber existido un hecho de trasgresión. El vínculo del sujeto con el trasgresor, la trasgresión y sus secuelas pueden llegar a transformarse de negativo a neutro o positivo. La fuente de la trasgresión, el objeto del perdón, puede ser el propio sujeto, otras personas o una situación percibida como fuera del control personal (enfermedad terminal, el destino, una catástrofe, una violación a un derecho humano básico). De cierta manera, al referirnos a la posibilidad o no de perdonar, aludimos a la posible modificación de determinados vínculos de apego entre una víctima y quien percibe como su victimario, así como a las consecuencias de sus acciones. La persona que perdona intenta transformar la valencia negativa del vínculo y combina tal modificación con una debilitación del tipo de vínculo. El self, una situación y otras personas pueden ser objeto de perdón. Es importante destacar que la acción psicológica de perdonar no excluye la opción de reclamar justicia si la motivación de tal reclamo no es simplemente vengativa. En términos generales los sentimientos de venganza revelan un estilo de apego negativo e incapacidad de perdonar. 


\section{Algunas consideraciones filosóficas}

Para Ricoeur (2004) los efectos de una falta (daño, herida) y de su perdón posible cruzan todas las operaciones constitutivas de la memoria, la historia y marcan el olvido de lo sucedido de un modo muy particular. El perdón, nos dice el pensador francés, si tiene sentido y existe, constituye el horizonte común de la memoria, la historia y el olvido. Es tan difícil dar perdón como recibirlo; también lo es concebirlo, porque pone al descubierto el lugar de la acusación moral. Tal falta es la presuposición existencial del perdón dada la condición histórica y la experiencia personal y colectiva inevitablemente marcada por la historia cultural de todo sujeto humano. La experiencia vivida (acoso, daño, herida) se da esencialmente en el plano de los sentimientos, de los estados afectivos. Se llega así al territorio de la imputabilidad. El sujeto se vincula con la acusación y se hace responsable de ella; sólo se puede hablar de perdón allí donde se puede acusar a alguien y este alguien es siempre un agente que puede hacer de diversas formas: hablando, narrando, actuando, imaginando.

El perdón puede ser pensado desde lo jurídico, lo político, la moralidad social: "es en el plano de lo judicial donde se plantea la temible cuestión de la imprescriptibilidad de los crímenes, que puede considerarse como la primera prueba importante de la problemática práctica del perdón" (Derrida, 1999, p.4). Cabe pues intentar estudiar la capacidad de perdonar al margen de las instituciones responsables del castigo formal. Generalmente es posible pensar en la posibilidad de comprender lo hecho por el victimario, lo que resulta psicológicamente difícil es absolverlo.

\section{¿Qué se perdona y a quién se perdona?}

Para Derrida el perdón se dirige a lo imperdonable o no es tal: "sólo hay perdón allí donde hubo algo imperdonable" (Derrida, 
1999, p.4). Es imposible pensar en la posibilidad de perdonar sin tener presentes los mandatos impuestos por una cultura determinada que pertenece a una herencia religiosa a la que denomina abrahámica pues engloba en ella el judaísmo, los cristianismos y los islamismos. Se trata de una cultura particular, pero hegemónica, en vías de universalización. Según Derrida, el perdón siempre está al servicio de una finalidad (rescate, redención, salvación, reconciliación) o intenta reestablecer una normalidad (psicológica, social, nacional). Mediante el trabajo de duelo, una terapia o ecología de la memoria no son conceptos puros o simples, sino que suponen complejidad: el perdón debería seguir siendo excepcional, a prueba de lo imposible.

El perdón enfrenta al sujeto con el culpable, no directamente con la falta cometida; la penalidad se remonta desde los actos realizados a sus autores.

Abel (1992), en un apéndice que escribe a una encuesta sobre el perdón, alude a la geografía de los dilemas, dilemas que encontramos en dos actos de discursos enfrentados: el del culpable y el de la víctima, a quien le correspondería expresar las palabras liberadoras: yo te perdono. ¿Se puede perdonar a quien no confiesa su falta? ¿Es necesario que quien enuncia el perdón haya sido el ofendido? ¿Puede uno perdonarse a sí mismo? ¿Sólo el ofensor está habilitado para pedir perdón?

Para Arendt (1998), estudiosa de los juicios por el genocidio nazi, la facultad del perdón está fundada en la presencia del otro; no se puede perdonar en soledad. Ella considera que los hombres son incapaces de perdonar lo que no pueden castigar e incapaces de castigar lo que les resulta imperdonable. ¿Desliga el perdonar al agente del hecho que ha cometido? Es importante tener presentes en todo momento al sujeto y la acción realizada dado que, si se separa a la persona de la falta concreta cometida, se está perdonando a un sujeto diferente. 
¿Hay relación entre perdón y olvido? Augé (1998) analiza estos temas tomando como referencia ciertos ritos africanos y propone lo siguiente: para retornar al pasado hay que olvidar el presente, como en los actos de posesión. Para reencontrar el presente es necesario suspender los vínculos con el pasado y el futuro. Para abrazar el futuro hay que olvidar el pasado en un gesto de inauguración. El olvido siempre se conjuga en presente.

\section{Psicología y perdón}

Las primeras investigaciones empíricas sobre el perdón fueron realizadas por Darby y Schlenker (1992), quienes analizaron los efectos de las disculpas frente a acusaciones y castigos en niños de 6, 9 y 12 años. Estos investigadores emplearon viñetas con un personaje central al que llamaron Pat. Encontraron que Pat (según los relatos de los niños) perdonaba más si los personajes formulaban pedidos de disculpas bien fundamentados.

Weiner, Graham, Meter y Zmuidinas (1991) investigaron si el impacto de los pedidos públicos de disculpas modificaban las percepciones de determinados comportamientos, en una muestra de estudiantes universitarios. Encontraron que las confesiones espontáneas tenían más efecto en la tendencia a perdonar que las confesiones producidas con posterioridad a ser culpado o acusado de algo hecho.

Enright (1994) y su grupo de investigadores en psicología evolutiva fueron los iniciadores de una serie de estudios sobre el desarrollo de la capacidad para perdonar tomando como base teórica de sus trabajos las ideas de Kohlberg acerca del razonamiento moral y utilizando como procedimiento para la obtención de información la presentación de situaciones con dilemas morales. A cada etapa propuesta por Kohlberg le corresponde una en el modelo 
planteado por Enright. Así, en las etapas más tempranas encuentran que el perdón aparece si el acusado previamente ha sido objeto de venganzas y castigos. En las etapas intermedias la posibilidad de perdonar surge sólo si hay presiones de parte de otros con significación para el sujeto. Sólo en el nivel más alto, el perdón es considerado como una actitud incondicional que promueve el bienestar. En esta última etapa es donde pueden encontrarse las principales diferencias entre las concepciones de Enright, para quien el perdón no supone ningún tipo de reciprocidad, y Piaget. En términos generales, jóvenes, adultos y personas mayores consideran que el perdón está ligado a actitudes filosóficas o religiosas. Subkoviak y colaboradores (1995) utilizan, en lugar de los dilemas morales antes mencionados, un inventario auto-administrable (Enright Forgiveness Inventory) respondido por estudiantes universitarios y miembros de sus respectivas familias. Los resultados obtenidos indican que los adultos revelan mayor capacidad para perdonar que los adolescentes, así como la existencia de correlaciones positivas en las díadas padres-hijos: padres e hijos perdonan de manera semejante, al menos ante situaciones donde existe un daño serio o profundo.

Empleando la técnica del análisis de clusters, Girard y Mullet (1997) encuentran los agrupamientos siguientes: 1) perdonar siempre: los participantes admiten que siempre es mejor perdonar que no hacerlo, 2) casi nunca perdonar: para estos sujetos el perdón es algo excepcional, 3) el perdón promueve la armonía social si existe el pedido de disculpas; está vinculado con la proximidad social y afectiva entre ofensor y ofendido, así como con las presiones del grupo.

La variable o constructo perdonar puede considerarse como acumulativa dado que distintos tipos de factores (edad, género, admisión de la ofensa, presión grupal, creencias religiosas) agregan su efecto a los ya existentes. 


\section{Perdón y arrepentimiento}

Cuando una persona lastima, hiere o comete una trasgresión que afecta a otra, esa acción crea, de alguna manera, una deuda interpersonal. Perdonar supone en cierta forma su cancelación, proceso que puede concretarse por canales diversos: cognitivos, afectivos, conductuales, psicosociales. Es necesario tener en cuenta que el arrepentimiento es tan importante como el perdón, dado que el arrepentimiento no sólo facilita la acción de perdonar sino que produce cambios positivos en la salud psíquica y física de quien puede expresarlo. Considerados en su vinculación dialéctica, arrepentirse y perdonar son ambos importantes para el logro de mejores vínculos interpersonales. Si sólo se considera una perspectiva, la de la víctima o el victimario o perpetrador, por ejemplo, pareciera que sólo se trata de un proceso subjetivo, intrapsíquico. Pero, en la vida cotidiana, los incidentes que conllevan algún tipo de trasgresión o daño involucran a amigos, parientes, compañeros de trabajo, parejas, por lo cual también es necesario abordar su estudio desde un nivel interpersonal, vincular.

Se designa víctima a quien sufre el daño o cree haberlo sufrido; el victimario o trasgresor es quien ha cometido el hecho inmoral o causado el daño. Generalmente las trasgresiones son mutuas $y$, en muchas situaciones, una persona puede jugar ambos roles. Así, a modo de ejemplo, una niña golpeada por su hermano mayor se transforma en victimaria cuando reacciona destrozando las hojas del libro que él está leyendo.

Las manifestaciones de perdón y arrepentimiento pueden ser implícitas o explícitas. Las denominadas explícitas hacen referencia directa a la presencia de lo adeudado y a la decisión de cancelación: yo te perdono lo que hiciste. Algunas veces estos tipos de expresiones pueden generar enojo o desagrado si no han sido solicitadas, dado que el victimario puede sentir que no ha hecho daño 
alguno y sentirse injusta o innecesariamente perdonado. Las manifestaciones implícitas aluden de manera indirecta a expresiones del tipo "dejémoslo asî", "no es nada serio" o "no hay problema". No siempre requieren el uso de palabras.

Perdón no es sinónimo de reconciliación. Se puede perdonar de manera independiente, sin que se concrete reconciliación alguna (Worthington, 1998), si bien tanto el arrepentimiento como el perdón pueden favorecerla. Una reconciliación supone el reestablecimiento de la confianza así como el deseo de reinstaurar un vínculo.

Existen consecuencias positivas y negativas de arrepentirse y perdonar. Entre las primeras figuran la reducción de sentimientos de culpa y angustia. La gente que escribe acerca de las consecuencias emocionales de acontecimientos traumáticos disminuye su tensión emocional y malestar físico (Pennebaker, 1995). Ciertos tipos de barreras dificultan o impiden el poder expresar arrepentimiento. En general, el victimario siente que se está exagerando lo que ha hecho, que las víctimas están sobreactuando. Los perpetradores pueden sentir que han sido provocados por sus víctimas, por lo cual viven sus actuaciones como justificadas sin ser necesario arrepentimiento alguno. Por otra parte, el aceptar la responsabilidad de una ofensa o daño suele traer costos pragmáticos severos, por lo cual hay resistencia a la confesión y el arrepentimiento.

Otro obstáculo a la confesión y al arrepentimiento está dado por el sentimiento de vergüenza que generan. La culpa alude a un afecto negativo focalizado en un hacer específico generalmente acompañado por el deseo de reparar. La vergüenza, contrariamente, conlleva a que el sujeto total se sienta mal, expuesto, y desee desaparecer y esconderse. La vergüenza genera enojo, supersticiones, necesidad de acusar a otros, comportamientos agresivos y, en 
ciertas ocasiones, está ligada a deseos de venganza (Bies \& Tripp, 1996). Provoca sentimientos de autoprotección y formaciones reactivas. En muchos casos sentirse avergonzado da lugar a fuertes sentimientos de humillación.

También hay obstáculos o barreras que dificultan el pedir perdón: el temor a que la trasgresión vuelva a repetirse; el miedo a aparecer ante los demás como un sujeto débil y manipulable; la creencia de que si se perdona se está violando estándares judiciales; el dejar de percibir los beneficios que brinda jugar el papel de víctima: el lugar de víctima da poder para inducir culpa y disculpas, justifica tener sentimientos de rabia e indignación, permite lograr apoyo y simpatía de los demás.

Perdonar y arrepentirse, aunque con frecuencia son beneficiosos, suelen ser percibidos como muy riesgosos en determinados contextos.

\section{Personalidad y perdón}

La historia del campo de la Psicología de la Personalidad se homologa con la búsqueda de una unidad de análisis para el estudio del sujeto humano en tanto individualidad. En este sentido, McAdams (1995) sugiere que se requiere información relativa a tres niveles de análisis: 1) el estudio comparativo de los rasgos, 2) las relaciones del sujeto con el contexto, y 3) la integración de historias de vida. Un ejemplo del primer nivel lo ofrecen los estudios sobre los Cinco Factores de Personalidad pero, tal como sostiene Ryan (1995), los sujetos no pueden ser reducidos a rasgos dado que resultan insuficientes al momento de intentar comprender comportamientos individuales en contextos específicos. Los rasgos aluden al ser de un sujeto mientras que interesa poder acceder a su hacer ante determinadas situaciones o metas. Ya en el 
La capacidad para perdonar desde una perspectiva psicológica

tercer nivel importan la construcción de la identidad y las narrativas de vida que dan cuenta de cómo es percibida la conformación del self. En este sentido, también la capacidad para perdonar puede ser analizada tomando en cuenta los tres niveles de análisis mencionados.

Quienes definen el perdón en términos de rasgo de personalidad (Roberts, 1995) lo consideran una virtud o disposición, llegando a proponer el concepto de inteligencia espiritual, relacionando la capacidad de perdonar con la humildad y la gratitud. Otra forma de estudio propone analizar estilos o tipos de personalidad y su incidencia en la capacidad para perdonar.

Algunas ideas sobre narcisismo y perdón son de interés. Ellis (1898) incorpora el concepto de narcisismo para describir cierta forma de autoerotismo masculino y Freud (1914) lo considera una etapa normal en el desarrollo infantil. Kernberg (1975) analiza el narcisismo como una configuración patológica de personalidad. Las características narcisísticas de personalidad están muy relacionadas con el no ser capaz de perdonar. Los aspectos interpersonales indican altos niveles de competitividad, ambición, tendencia a asumir posiciones de liderazgo, a actuar sin tener muy en cuenta la opinión de los demás, a esperar que los otros reconozcan la existencia de cualidades o talentos especiales. Son autosuficientes, audaces, persuasivos, con la suficiente capacidad de seducción para ganar adictos a sus causas personales. Carecen del sentido de reciprocidad social y revelan muy baja empatía, son demandantes, bastante egoístas, poseen autoestimas muy vulnerables, muestran necesidad de admiración e hipersensibilidad ante las injurias, las críticas y los fracasos. La gratificación vengativa, la revancha, es la respuesta más frecuente frente a los daños y perjuicios (Millon, 1998). En términos generales, el perfil narcisista es la antítesis del de una persona capaz de perdonar. 
Algunos estudiosos del tema (Vitz, 1994) se refieren a las últimas décadas del siglo XX como las de mayor florecimiento del narcisismo desmedido; una cultura que alienta el individualismo, la competitividad y los logros personales no recibe con simpatía el concepto perdonar ipodremos reemplazar en el siglo XXI el auge del narcisismo por una sociedad integrada por sujetos más dispuestos a la humildad, los lazos sociales y el perdón?

\section{Obstáculos para poder perdonar}

El proceso del perdón puede enfrentar situaciones que dificulten su concreción y que deben ser siempre tenidas en cuenta.

El tema puede analizarse, sintéticamente, tomando en consideración tres ámbitos importantes:

- Político-social: ciertos tipos de delito, prácticas de trabajo no éticas, despidos laborales que no respetan la legislación vigente y discriminaciones étnicas o religiosas pueden ocasionar daños o lesiones cuyo perdón es difícil de asumir por el victimario.

- Relaciones romántico familiares: en muchos casos de divorcios o separaciones vinculares, donde ha habido fuertes experiencias de infidelidad reiteradas así como violencia sexual o doméstica, no siempre hay predisposición para planteos de perdón.

- Prácticas médicas: en casos de enfermedades terminales, SIDA, internaciones psiquiátricas por problemas con el consumo de alcohol o drogas, así como cuando se sospechan errores o mala praxis, se generan sentimientos de enojo y desconsuelo y crisis familiares a veces muy agudas que dificultan hacer cualquier planteo sobre el perdón. 
En términos generales hay que ser cautelosos ante situaciones en las que el victimario no siente culpa o remordimiento alguno por el daño cometido, cuando la trasgresión concretada es muy severa o si las heridas que un hecho ha provocado son muy recientes por lo que hay todavía confusión acerca de lo sucedido. Todo ello requiere que la capacidad de perdonar deba ser evaluada teniendo en cuenta diferentes niveles: 1) la víctima, 2) el victimario, 3) la relación víctima/victimario, 4) el tipo de ofensa o daño causado, y 5) las interrelaciones posibles entre los cuatro niveles mencionados.

\section{Metodología}

Se trata de un estudio exploratorio, descriptivo-correlacional.

\section{Instrumento}

Tomando como marco de referencia las concepciones de Margrave y Selles (1997) acerca del perdonar, se diseñó una escala auto-administrable para ser respondida por población general adulta. Para los autores mencionados perdonar supone un esfuerzo para restaurar sentimientos de amor y confianza de manera tal que tanto víctimas como victimarios puedan poner punto final a un vínculo destructivo, dar la oportunidad de compensación a fin de lograr que la víctima pueda percibir a su ofensor en términos no amenazantes y poder analizar en forma conjunta la experiencia vivida y el daño provocado.

Para el diseño de la escala se tuvieron en cuenta las tres dimensiones siguientes: el sí mismo (self), los otros y la situación. Se incorporaron dos ítemes para evaluar el impacto de ciertas creencias (poder superior, destino) sobre el poder perdonar. Se 
diseñó una escala integrada por 20 ítemes con cuatro opciones de respuesta: casi siempre falso para mí, a veces falso para mí, a veces verdadero para mí, casi siempre verdadero para mí.

La consigna fue la siguiente: "Durante nuestras vidas nos suceden hechos negativos que pueden ser consecuencia de nuestras propias acciones, las acciones de otras personas o de situaciones que no podemos controlar. Con el paso del tiempo, podemos tener sentimientos negativos hacia nosotros mismos, otras personas o la situación pasada. Le solicitamos que considere DE QUÉ MANERA REACCCIONA USTED HABITUALMENTE FRENTE A ESE TIPO DE SITUACIONES NEGATIVAS y pensando en ello responda a los siguientes ítemes. Tiene cuatro opciones de respuesta $(1,3,5,7)$ para cada uno: 1: Casi siempre falso para mí. 3: A veces falso para mí. 5: A veces verdadero para mí. 7: Casi siempre verdadero para mí."

\section{Participantes}

Se trabajó con la técnica de muestreo intencional. La participación fue anónima y voluntaria. Respondieron la escala 800 personas adultas ( $50 \%$ varones, $50 \%$ mujeres) con una edad promedio de 38 años para ambos sexos. Residen en la ciudad de Buenos Aires el $60 \%$ de los varones y el $54 \%$ de las mujeres. El $20 \%$ de mujeres y varones viven en el conurbano bonaerense. El $10 \%$ de los varones y el $14 \%$ de las mujeres son migrantes internos.

\section{Procedimiento}

Para la obtención de datos se utilizó la escala CAPER antes mencionada, cuya validez lingüística fue probada en un estudio piloto $(\mathrm{N}=40)$ en el que se pidió a los participantes que leyeran 
La capacidad para perdonar desde una perspectiva psicológica

los ítemes redactados y sugiriesen modificaciones en los casos en los que la comprensión lectora era poco clara. Está integrada por 20 ítemes que evalúan las dimensiones self, otros, situación y creencias. Se obtiene una puntuación total.

Se incluyeron en la técnica preguntas sobre sexo, edad, lugar de nacimiento, ocupación y educación, lugar de residencia actual, además de una pregunta sobre nivel de religiosidad y otra sobre si considera importante poder perdonar y por qué.

La administración estuvo a cargo de estudiantes de la Facultad de Psicología de la UBA, inscritos en la cátedra 2 de Teoría y Técnicas de Exploración y Diagnóstico, durante el año 2004, supervisados por los auxiliares docentes psicólogos.

\section{Resultados}

Se han calculado en primer término los valores promedios y de dispersión, indicando en las tablas que se presentan, si las diferencias entre las Medias Aritméticas encontradas son estadísticamente significativas.

\section{Cuadro 1}

Medias y desviaciones típicas para las cuatro dimensiones según género

\begin{tabular}{lrrrl}
\hline \multirow{2}{*}{ Dimensión } & \multicolumn{2}{c}{ Varones } & \multicolumn{2}{c}{ Mujeres } \\
\cline { 2 - 5 } & $M$ & $d t$ & $M$ & $d t$ \\
\hline Self & 28,7 & 5,2 & 28,8 & 5,1 \\
Otros & 26,7 & 6,6 & 27,1 & 6,2 \\
Situación & 26,3 & 5,7 & 27,0 & 5,7 \\
Creencias & 6,6 & 3,9 & 7,5 & $3,9^{* *}$ \\
\hline Total & 88,3 & 13,6 & 90,3 & $13,9^{*}$ \\
\hline \multirow{2}{*}{$\mathrm{p} \geq 0.05$ ( z 2.01), ** $\mathrm{p} \geq 0.01(\mathrm{z} 3.21)$} & &
\end{tabular}


Sólo se han constado diferencias con significación estadística para la puntuación total obtenida en la escala y para la dimensión creencias. El valor promedio total obtenido es mayor en la muestra femenina como así también el papel asignado por las mujeres al impacto de las creencias ( $t$ de Student).

Se calculó chi cuadrado a fin de estimar la posible asociación entre sexo e importancia del perdonar, encontrándose un nivel de asociación positiva (significación $\geq 0.004$ ). Las mujeres revelan mayor capacidad para perdonar que los varones, en la muestra analizada.

\section{Cuadro 2}

Medias y desviaciones típicas para las cuatro dimensiones según grupos de edad

\begin{tabular}{lrrrrrr}
\hline \multirow{2}{*}{ Dimensión } & \multicolumn{2}{c}{$22-30$ años } & \multicolumn{2}{c}{$31-43$ años } & \multicolumn{2}{c}{$44-60$ años } \\
\cline { 2 - 7 } & \multicolumn{1}{c}{$\boldsymbol{M}$} & $d t$ & \multicolumn{1}{c}{$M$} & $d t$ & \multicolumn{1}{c}{$M$} & $d t$ \\
\hline Self & 28,7 & 4,9 & 29,1 & 5,4 & 28,4 & 5,2 \\
Otros & 26,2 & 6,2 & 27,3 & 6,7 & 27,1 & 6,3 \\
Situación & 26,6 & 5,8 & 27,0 & 5,8 & 26,3 & 5,6 \\
Creencias & 6,6 & 3,9 & 7,2 & 3,9 & 7,4 & $4,1^{*}$ \\
\hline Total & 88,0 & 12,9 & 90,6 & 13,8 & 89,3 & 14,46 \\
\hline
\end{tabular}

* $p \geq 0.05$ ( $z \quad 2.03$ )

El peso de las creencias aumenta con la edad, es más elevado (con la misma significación estadística) para el grupo de 44 a 60 años que para los más jóvenes (Cuadro 2).

\section{Propiedades psicométricas}

En primer lugar, se analizó la capacidad de discriminación de los ítemes, es decir la sensibilidad de cada reactivo para diferenciar 
sujetos ubicados en los extremos superior e inferior del rango de puntuaciones, verificándose índices adecuados (distintos de cero y no negativos), salvo para el ítem 12 , tanto si se considera el cálculo de la correlación corregida entre la puntuación total y el ítem, como si se tiene en cuenta la correlación corregida del ítem con cada puntuación parcial o dimensión prevista en el diseño de la escala (Self, Otros, La Situación y Creencias que determinan el perdonar).

En segundo lugar, se calculó un análisis de componentes principales mediante criterio de raíz latente, con rotación Equamax con Kaiser, que aisló seis factores que explican el $53 \%$ de la varianza total, porcentaje que resulta aceptable comprobándose que ninguno de ellos se diferencia excesivamente del resto en virtud de la proporción de varianza que explica $(10.80 \%, 10.62 \%$, $9.31 \%, 7.99 \%, 7.64 \%$ y $6.49 \%$, respectivamente). Las medidas de adecuación muestral y de ajuste de la extracción resultan adecuadas (Kaiser-Meyer-Olkin $=.738$; Test de Esfericidad de Bartlett: $\left.x^{2}=1955.704,171 \mathrm{gl}, \mathrm{sig}=.000\right)$. El ítem 12 , que ya presentaba inconvenientes en cuanto a su capacidad discriminativa, tampoco se comporta adecuadamente en el análisis factorial, exhibiendo cargas dobles, superiores a .40. Esta matriz factorial rotada se escogió luego de varios intentos de combinar diversos métodos de extracción con diferentes métodos ortogonales y oblicuos de rotación, debido a que era la que presentaba los mejores índices de ajuste, la mayor coherencia teórica, los mayores porcentajes de varianza explicada y la que permitía conservar la mayor cantidad de elementos. La consistencia (Alfa de Cronbach) por factor es de $.58, .60, .54, .62, .41$ y .20 , respectivamente. Estos índices resultan adecuados si se contempla el escaso número de reactivos incluido en cada subescala, cuestión que afecta la fiabilidad, 4 ítemes para los Factores 1 y 2; 3 para los Factores 3, 5 y 6; y 2 elementos para el Factor 4. De todas maneras, debe destacarse que este último factor, con dos reactivos, exhibe un Alfa de .62, resultado que denota una excelente consistencia; inversamente, es 
necesario advertir que el Factor 6 es el que verifica una menor consistencia, aunque el hecho de que conste sólo de tres ítemes permite cierta tolerancia para este índice. La consistencia interna de la escala total es de .61 .

En el Cuadro 3 se indican los datos relativos al nivel de religiosidad según cuatro categorías y una quinta correspondiente a la ausencia de respuesta a este ítem.

\section{Cuadro 3}

Porcentajes de nivel de religiosidad según género

\begin{tabular}{lccccc}
\hline & $\begin{array}{c}\text { Muy } \\
\text { religioso } \\
\%\end{array}$ & $\begin{array}{c}\text { Algo } \\
\text { religioso } \\
\%\end{array}$ & $\begin{array}{c}\text { Poco } \\
\text { religioso } \\
\%\end{array}$ & $\begin{array}{c}\text { Nada } \\
\text { religioso } \\
\%\end{array}$ & $\begin{array}{c}\text { No } \\
\text { responde } \\
\%\end{array}$ \\
\hline Varones & 8 & 36 & 27 & 28 & 0,5 \\
Mujeres & 11 & 48 & 24 & 17 & 0,8 \\
\hline
\end{tabular}

El $44 \%$ de los varones y el $59 \%$ de las mujeres se consideran algo o muy religiosos, en tanto que el $28 \%$ de los hombres y el $17 \%$ de las mujeres admiten ser nada religiosos (Cuadro 3 ).

El cálculo de rho permitió constatar que el género y la edad (tomada según las tres categorías mencionadas en el Cuadro 2) correlacionan negativamente con el nivel de religiosidad (nivel de significación $\geq$ al 0.001). Las mujeres se reconocen más religiosas que los varones y a mayor edad es menor el grado de religiosidad auto-informado para ambos géneros. No se ha encontrado asociación entre religiosidad y el nivel educativo.

Para ambos sexos, los ítemes marcados "casi siempre verdadero" con mayor frecuencia ( $40 \%$ o más) son:

3. Aprendo de los errores, entiendo como soy. 
5. Se entiende lo sucedido con el paso del tiempo.

14. El tiempo ayuda a comprender hechos negativos.

Por otro lado, los ítemes señalados "casi siempre falso" con alta frecuencia ( $40 \%$ o más) son, para los varones:

19. Creer en un poder superior.

20. Uno se merece lo que le ha pasado.

13. Pensar constantemente en hechos que no controlan.

Y para las mujeres:

20. Una se merece lo que le ha pasado.

17. Cuesta aceptar que nadie es responsable de lo negativo.

19. Creer en un poder superior.

Las principales diferencias entre valores promedio encontrados ( $t$ de Student, $\mathrm{p} \geq 0.01)$ según género son:

Mujeres: creen más en un poder superior (ítem 19) y sienten rencor casi permanente hacia el victimario (ítem 7).

Varones: les cuesta más admitir que les sucedió algo malo (ítem 4) y son indiferentes (ítem 12).

Cuadro 4

¿Es importante poder perdonar?

\begin{tabular}{lcc}
\hline & $\begin{array}{c}\text { Varones } \\
\%\end{array}$ & $\begin{array}{c}\text { Mujeres } \\
\%\end{array}$ \\
\hline Sí & 88 & 95 \\
No & 10 & 4 \\
\hline
\end{tabular}

No se han analizado en este trabajo las respuestas dadas a la pregunta ¿por qué?, en tanto fundamento de lo contestado (sí o no). 


\section{Discusión}

Se han presentado datos preliminares obtenidos a partir de la administración de la escala CAPER a una muestra intencional de adultos de población general urbana. En otro trabajo redactado posteriormente al presente (Casullo \& Fernández Liporace, en prensa) se analizan los estudios psicométricos específicos realizados, que permiten verificar que se trata de un instrumento con validez estructural y consistencia interna en sujetos adultos. Se han podido determinar seis factores o componentes principales que pueden explicar más del $50 \%$ de la varianza; estudios sobre confiabilidad determinan una consistencia interna de 0.61 .

Interesa destacar que el porcentaje de personas que consideran importante poder perdonar es elevado: $88 \%$ de los varones y 95\% de las mujeres han respondido de forma positiva.

Si se toma en cuenta la variable género, se advierte que las mujeres son más perdonadoras que los hombres, incidiendo en ello principalmente la dimensión de las creencias, las que parecen tener más peso a medida que se cumplen años, influyendo más en el grupo de personas mayores. Este dato podría relacionarse con el nivel de religiosidad reconocido, significativamente más alto en la muestra femenina. Las mujeres tienden a admitir más influencia de un poder superior y sienten más rencor hacia el victimario que los hombres. A ellos les resulta más difícil admitir que algo negativo les ha sucedido y tienden a mostrarse más indiferentes.

Los sujetos de ambos sexos reconocen que se aprende de los errores y que el paso del tiempo ayuda a poder perdonar. Para los hombres parece tener menos sentido pensar en aquello que no pueden controlar.

Como se ha expresado en párrafos iniciales de este trabajo, la capacidad de perdonar debe ser evaluada teniendo en cuenta 
La capacidad para perdonar desde una perspectiva psicológica

diferentes niveles: 1) la víctima, 2) el victimario, 3) la relación víctima/victimario, 4) el tipo de ofensa o daño causados, 5) las interrelaciones posibles entre los cuatro niveles mencionados.

Futuros estudios deberán tomar en consideración tales niveles de análisis.

Se considera necesario desarrollar técnicas en idioma castellano sobre los temas que propone la Psicología Positiva o Salugénica contemporánea, que evalúen creencias y concepciones émicas (particulares de un grupo cultural) en el contexto de la realidad sociocultural sudamericana. En este sentido, el estudio exploratorio presentado puede considerarse pionero en relación con lo planteado y el tema abordado.

\section{Referencias}

Abel, O. (1992). El perdón: quebrar la deuda y el olvido. Madrid: Cátedra.

Angyal, A. (1952). The convergence of psychotherapy and religion. Journal of Pastoral Care, 5(4), 4-14.

Arendt, H. (1998). La condición humana. Barcelona: Paidós.

Augé, M. (1998). Las formas del olvido. Barcelona: Gedisa.

Beaven, R. H. (1951). Christian faith and psychological study of man. Journal of Pastoral Care, 5, 53-60.

Behn, S. (1932). Concerning forgiveness and excuse. Archiv fuer die Gesante Psychologie, 86, 55-62.

Bies, R. J. \& Tripp, T. M. (1996). Beyond distrust: Getting even and the need for revenge. En R. M. Kramer \& T. R. Tyler (Eds.), Trust in organizations: Frontiers for theory and research. California: Sage.

Boon, S. D. \& Sulsky, L. M. (1997). Attributions of blame and forgiveness in romantic relationships. A policy-capturing 
study. Journal of Social Behavior and Personality, 12, 1944.

Casullo, M. M. \& Fernández Liporace, M. M. (en prensa). La capacidad de perdonar. Un estudio psicométrico.

Darby, B. W. \& Schlenker, R. B. (1982). Children's reactions to apologies. Journal of Personality and Social Psychology, 43, 742-753.

Derrida, J. (1999). Le siècle et le pardon. París: Le Monde des Débats.

Ellis, H. (1898). Sexual inversion. Londres: Wilson y MacMillan.

Enright, R. D. (1994). Piaget on the moral development of forgiveness: Identity or reciprocity? Human Development, 37, 63-80.

Enright, R. D., Santos, M. J. D. \& Al-Mabuk, R. (1989). The adolescent as forgiver. Journal of Adolescence, 12, 99-110.

Enright R. D. \& Coyle, C. T. (1998). Researching the process model of forgiveness within psychological interventions. En E. L. Worthington (Ed.), Dimensions of forgiveness (pp.139161). Filadelfia: Templeton Foundation Press.

Fitzgibbons, R. P. (1986). The cognitive and emotive uses of forgiveness in the treatment of anger. Psychotherapy, 23, 629-633.

Freud, S. (1914). Obras completas (Vol. 4). Buenos Aires: Amorrortu. Girard, M. \& Mullet, E. (1997). Propensity to forgive in adolescents, young adults, older adults and elderly people. Journal of Adult Development, 4, 209-220.

Hargrave, T. D. \& Sells, J. N. (1997). The development of a forgiveness scale. Journal of Marital and Family Therapy, 23, 41-53.

Hope, D. (1987). The healing paradox of forgiveness. Psychotherapy, $24,240-244$.

Jampolsky, G. G. (1980). The future is now. Journal of Clinical Child Psychology, 9, 184-192.

Kernberg, O. (1975). Borderline conditions and pathological narcissism. Nueva York: J. Aronson. 
La capacidad para perdonar desde una perspectiva psicológica

Kohlberg, L. (1976). Moral stages and moralization. The cognitive developmental approach. En T. Lickone (Ed.), Moral development and behavior: Theory, research and social issues. Nueva York: Holt, Rinehart \& Winston.

McAdams, D. P. (1995). What do we know when we know a person? Journal of Personality, 63, 365-396.

McCullough, M., Pargament, K. I. \& Thoresen, C. E. (2000). Forgiveness. Theory, research and practice. Nueva York: Guilford Press.

Millon, T. (1998). DSM narcissistic personality disorder. En E. F. Ronningstam (Ed.), Disorders of narcissism: Diagnostic, clinical, and empirical implications. Washington: APA.

Pennebaker, J. W. (1995). Emotion, disclosure and self. Washington: APA.

Piaget, J. (1932). El juicio moral en la infancia. París: Alcan.

Ricoeur, P. (2004). La memoria, la historia, el olvido. Buenos Aires:

Fondo de Cultura Económica.

Roberts, R. C. (1995). Forgiveness. American Philosophical Quarterly, 32, 289-306.

Rokeach, M. (1973). The nature of human values. Nueva York: Free Press.

Ryan, R. M. (1995). Psychological needs and the facilitation of integrative processes. Journal of Personality, 63, 397-427.

Subkoviak, M. J., Enright, R. D., Wu, C. R. \& Gassin, E. A. (1995). Measuring interpersonal forgiveness in late adolescence and middle adulthood. Journal of Adolescence, 18, 641-655.

Vitz, P. C. (1994). Psychology as religion: The cult of self-worship. Minnesotta: Eerdmans.

Weiner, B., Graham, S., Peter, O. \& Zmuidinas, M. (1991). Public confession and forgiveness. Journal of Personality, 59, 281312.

Worthington, E. I. (1998). Dimensions of forgiveness. Psychological research and theological perspectives. Filadelfia: Templeton Foundation Press. 